\title{
Co-Relational Study between Organizational Climate and Job Performance of Private School Teachers
}

\author{
Rajesh Kumar Singh ${ }^{a}$, Prof. Kavita Varma ${ }^{b}$ \\ ${ }^{a}$ Research Scholar, Faculty of Education, GLA University, Mathura, Uttar Pradesh, India. \\ E-mail: rk.singh@gla.ac.in

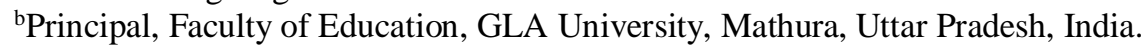 \\ E-mail: kavita.varma@gla.ac.in
}

Article History: Received: 11 January 2021; Accepted: 27 February 2021; Published online: 5 April 2021

\begin{abstract}
The current study investigated relationship between Organizational climate and Job Performance of school Teachers. Descriptive Survey method is used for the research to accomplish the objective of the study. A sample of 116 higher secondary school teachers working in private schools were taken from Mathura district of Uttar Pradesh by convenience sampling technique. Mean, Standard deviation and Pearson Product Moment Correlation is used for analyzing the collecting data. The findings revealed that the reoccurs a significant correlation between Organizational Climate and Job Performance towards school teachers.
\end{abstract}

Keywords: Organizational Climate, School Teachers, Job Performance, Correlation.

\section{Introduction}

Education is the basis of current a fruitful lifetime. Education as exact by Senath Jackson, (2008) is "an act or process of imparting or acquiring general knowledge, developing the powers of reasoning and judgment and generally preparing oneself for mature life". Education assistances as the worth to get everywhere the required deviations in lifetime to produce a generation of right eons people's connective to the growth of one's distinct age as fine as all human beings in the expansion.

The noteworthy ingenuity of education is to carry indication, connect the events of decent manner and get occupational capability amongst people so as to cultivate them skillfully. Deprived of education it is safe for young people to achieve fruitful recognized era.

An organization is a common existence that has a combined goal and is connected to an exterior state. The period is subsequent from the Greek term 'organ on', herself subsequent from the accustomed word 'argon' which funds "organ" a unit for an exact job. An organization is distinct by the basics that are slice of it, its declaration, its independence, and its orders of action related to exterior measures. Each organization possesses an exact kind of climate in which its elements profession and exertion in consistency. Organizational climate is comprised of mixture of customs, ethics, predictions, directions and procedures that effect work motivation, dedication and work constituent or departmental performing of a being. An organization is a build where the varied connections drive effortlessly and certainly to recover the parts and the drives of the organization, proposal a dynamic organization climate.

Education is the procedure to sequence the followers for the alteration in the lifetime circumstances. The alteration is the life era protracted procedure and lasts till the noticeable of life. The period 'adjustment' has dual minds in unique it is boundless procedure in which being fluctuations his conduct implementation to altering staterun to crop an extra pleasant association with themselves and paradise. In additional knowledge, adjustment is a state-run which is the ailment of agreement stretched by a distinct once we demand 'fine fitted'. In the contemporary generation, with all its difficulties and all its burdens, many people let their difficulties astounded. Persuaded people who be unsuccessful to flawless themselves to their surroundings effort to become the possessions that they request done small slices which might crucial into corruption others, detection themselves repeatedly disgruntled by circumstances they do not want appearance or cannot beneath, finally become neurotics of one caring. Static others, whose exterior manner never advanced severe adequate to include the politeness of the juries, however living dissatisfied, despairing survives.

Teaching is said to be a homeland building action and teacher is the performances, therefore job performance of teachers is not predisposed architect of the forthcoming. From peers teacher is by the sort of association (Distance or Conventional), somewhat the vigorous constituent of educational system who save sup lighter of issues likes salaries and promising facility circumstances which not only development at full blossom in order to 
inform the entire creation sound effects optimistic but also improves educators Job Performance Excellence of education is significant important instrument in its pointers. Essential assistances of educators like similar be contingent on numerous influences like information, education capability to explain, teaching excellence, reading ability and research capability displays capability, amenities delivered by the association, social optimistic relationship and influences positively on educators' job amendment of the educator, satisfaction of job, emotional constancy and performance. Entirely of these features have a pronounced impact on the job performance. An association is a communal unit that has a cooperative goal line and is Performance in job is the principal feature of an educator which echoes not connected to an exterior atmosphere. Solitary the development of the distinct but of the whole association. Organization is a small the general public encompassing of physical Job Performance is classically theorized as movements and (employees) and legislative (rules \& regulations) fundamentals performances that are below the controller of the distinct that subsidize operative collaboratively to reach goalmouths and purposes of to the goalmouths of the association. Specific association under a convivial environment. Numerous Job performance is pragmatic set of humanoid conduct which can be proficient rudiments of educators like informative level, location and restrained to evaluate the attainment level of an distinct, it is an distance of period consumed in an association had important possessions on vital feature for work efficiency of an distinct, consequently numerous organizational constituents like climate and resources achievement or letdown of an edifice be contingent upon the job performance of management of that specific association. Numerous job performance procedures like teaching personnel, dependent upon features like distance of service, boldness times, amount of pupils and course arrangements per semester are in the direction of alteration and conventional environment. Staffs owning not connected to worldwide conduct calculating keenness/ high reaction replicates undesirable oldness in the direction of the firm pouring and period burden. Accountability and conduct are major sponsor to job satisfaction and exposed kind of environment. Supplementary organizational climate owns an important association with organizational citizenship behavior, educators' job satisfaction and Scheme psychological capital intervenes the relationship amid organizational climate and organizational citizenship behavior Members. Therefore, organizational characters in accomplishment of wanted instructive goalmouths.

\section{Objective}

(i) To find out the relationship between organizational climate and job performance of private school teachers.

\section{Hypothesis}

(ii) There occurs no significant relationship between Organizational Climate and job performance towards private school Teachers.

\section{Sample}

In the existing investigation, a sample of 116 private school teachers was carefully chosen from the Mathura district (U.P.). through convenience sampling technique and 30 schools selected through random sampling technique accounts as sample from entire population.

\section{Tools Used}

(i) Organizational Climate Inventory established by Somnath Chattopadhyay (2003). This organizational climate scale consisted 70 items. The maximum possible score on this scale is 350 and minimum score is 70 and it responded on a five-point scale.

(ii) Rating Scale to measure Job Performance built by the investigator.

\section{Statistical Technique}

In the current research, to investigate the relationship of organizational climate with the job performance towards private school teachers, Pearson Product Moment coefficient of Correlation was applied.

\section{Results}

To determine the relationship of organizational climate towards job performance among private school teachers, linear regression analysis was carried out with the help of correlation analysis. Correlation matrix is formed which shows inter correlation among the variables of the study shown in Table 1.

Table 1. Correlation Matrix Exhibiting Relationship Amongst Organizational Climate and Job Performance 


\begin{tabular}{lcc}
\hline Variables & Organizational Climate & Job Performance \\
\hline Organizational Climate & 1 & \\
\hline Job Performance & 0.536 & 1 \\
\hline$* *$ Significant at 0.01 level, *Significant at 0.05 level &
\end{tabular}

The matrix of coefficient of correlation of Table 1 indicates that organizational climate and job performance scores have significant and positive correlation $(\mathrm{r}=0.536)$. Correlations were calculated to determine to what extent organizational climate correlated with job performance. As can be seen in Table 1, significant positive correlations were formed for both variables. This results show that there is a strong relationship between organizational climate and job performance between private school Teachers.

\section{Conclusions}

It has been determined that there exists significant and positive relationship amongst organizational climate and job performance of private school teachers. The outcomes discovered that on organizational climate of school teachers as this vocation contains a particular chain of knowledge in succession from highest to lowest, the similar outcomes have been stated by Armstrong (1996) in the discoveries of his research led on forecasting job performance. It has been determined that there exists significant positive relationship amongst Organizational Climate and Job Performance of Teaching educators as the outcomes exposed positive climate improves improved job performance, the similar outcomes have been stated by Adeyemi (2008) in the outcomes of his research directed on organizational climate and educators job performance.

\section{References}

1. Adeyemi, T.O. (2008). Organizational Climate and teachers Job Performance in Primary Schools in On do state, Nigeria: An Analytical Survey. Asian Journal of Information Technology, 7(4), 138-145.

2. Armstrong. (1996). Predicting job performance: A comparison of expert opinion and research findings. Journal of Applied Psychology, 93(1), 108-124.

3. Blackl, J.S. (1990). The Relationship Among Social Adjustment, Job Performance and Expatriate Expectations, Ph.D Thesis: The Amos Tuck School of Business Administration, Dartmouth College, Hanover, New Hampshire.

4. Illmer, S.J. (2011). Definition of performance and performance measurement: Illmer Investment Performance Consulting. London: Horizon Publications.

5. Jackson, S. (2008). Dictionary of Education: London: New-way Publications.

6. Pradhan, S. (2012) Assessment of Motivation and Job Performance of Library and Information Science Professionals of the University Libraries of Gujarat: IASLIC Bulletin, 57(2), 111-121.

7. Scarpello, V., \& John, P.C. (1983). Job Satisfaction: Are All the Parts There? Personal Psychology, 36, 577- 600.

8. Sinclair, R.I. (1970). Educational Climate of Secondary School of Rajasthan: Ph. D. Thesis, Centre for Advanced Studies in Education, M.S. University Baroda.

9. Suresh, B. (2007). Social Adjustment and Job Performance of Rural and Urban College Teachers: Ph. D Thesis, Submitted to Guru Nanak Dev University, Amritsar.

10. Veena, M, Khadi, P.B., \& Gankar, V. (2003). Influence of social climate on Adolescents Adjustment. Journal of Community Guidance and Research, 20(3), 223-230. 